\title{
Quality of life in patients with ulcerative colitis treated surgically
}

\author{
Katarzyna A. Kozłowska', Grażyna Bączyk1, Piotr Krokowicz² \\ ${ }^{1}$ Department of Nursing, Faculty of Health Sciences, Poznan University of Medical Sciences, Poland \\ ${ }^{2}$ Department of General and Colorectal Surgery, Faculty of Health Sciences, Poznan University of Medical Sciences, Poland
}

Prz Gastroenterol 2014; 9 (4): 220-226

DOI: $10.5114 / p g .2014 .45104$

Key words: ulcerative colitis, quality of life, Inflammatory Bowel Disease Questionnaire, Short Form Health Survey-36.

Address for correspondence: Grażyna Bączyk, Department of Nursing, Faculty of Health Sciences, Poznan University of Medical Sciences, 11 Smoluchowskiego St, 60-179 Poznan, Poland, phone: +48 6165592 61, fax: +48 61655 92 66, e-mail: gbaczyk@ump.edu.pl

\begin{abstract}
Introduction: Ulcerative colitis belongs to the group of inflammatory bowel diseases. The specific symptoms and chronic nature of the disease significantly affect the quality of patients' lives. Quality-of-life assessment helps to define its determining factors as well as the efficiency of surgical procedures.

Aim: Quality-of-life evaluation of patients with ulcerative colitis treated surgically.

Material and methods: A retrospective review was carried out on 35 patients with ulcerative colitis, who were treated surgically in the Clinic of General and Colorectal Surgery, University of Medical Sciences in Poznan. The research tools used to assess the quality of life consisted of: the Inflammatory Bowel Disease Questionnaire, a Polish version of the Short Form Health Survey-36, and a questionnaire.

Results: The mean of the IBDQ scale was 152.51, and the median was 161. In this scale, a higher score indicates better quality of life. The situation in the subjective SF-36 scale is reversed: a lower score indicates better quality of life. The mean of the SF-36 was 115.94, and the median was 58. Many discrepancies in the field (e.g. the influence of determining factors) create a niche for further studies.

Conclusions: Moreover, quality-of-life evaluation may lead to better patient care, understanding their problems or treatment modifications, and finally may become a kind of therapy efficiency parameter.
\end{abstract}

\section{Introduction}

Contemporary medicine prefers a holistic approach to a patient. It consists of a clinical evaluation, physical examination, and quality-of-life evaluation. This last component is determined by a significant impact of health/illness on the physical, mental, and social condition of the patient. It particularly applies to people who suffer from chronic diseases, including ulcerative colitis (UC) [1].

Ulcerative colitis is a nonspecific inflammatory bowel disease. It manifests primarily with bloody diarrhoea and abdominal pain. The disease spreads proximally, starting from the anus. So far, its aetiology is unknown. The methods of treatment are pharmacotherapy, surgery, and following an appropriate diet [2].

According to epidemiological data, the prevalence of UC has increased in recent years. The disease af- fects mainly young people, and the peak incidence is between the ages of 20 and 40. In European population, 10 out of 100,000 people annually suffer from UC $[2,3]$.

There are many definitions of quality of life $(\mathrm{Q} o \mathrm{~L})$, more or less accurately reflecting its meaning [4]. The variety of definitions probably reflects the complexity of the issue, which has many dimensions, depending on the perspective from which the subject is being examined and its axiology. A conceptual understanding of the term QoL is also crucial here - using the following synonyms: happiness, well-being, contentment, good and fulfilled life $[1,5]$. A WHO Committee defined quality of life as "the individual's perceptions in the context of their culture and value systems, and their personal goals, standards, and concerns" [5]. Quality of life, as a medical concept, is closely related to the term "health" $[6,7]$. It is also indicated by Sęk, who adds that QoL has a subjective and objective dimension [4]. Today, 
owing to the work of Flanagan, two taxonomies of the term quality of life are distinguished - Health Related Quality of Life (HRQL) and Non-health Related Quality of Life (NHRQL). The HRQL includes psychological, somatic, physical, and social areas, and NHRQOL includes personal and environmental areas [7, 8].

\section{Aim}

The main objective of the research was quality-of-life evaluation in patients with ulcerative colitis after surgery. Specific objectives included evaluation of each of the quality-of-life areas and the influence of selected factors on the quality of life in patients with UC after surgical treatment.

\section{Material and methods}

The study was conducted on a group of 35 patients diagnosed with ulcerative colitis, who were treated surgically (restorative proctocolectomy with formation of an internal pouch and complete removal of the large intestine with the emergence of ileostomy) after an average of 6 months post-operation. The study was conducted 3 months after surgery. Respondents were treated in the Clinic of General and Colorectal Surgery at the Poznan University of Medical Sciences. The study was conducted in the years 2012-2013. Patients from the test group gave their written consent to conduct the survey. Consent for performing the study was obtained from the Ethical Commission of the University of Medical Sciences in Poznan (No. 126/07)

For the purpose of the research on the quality of life, Polish versions of the Inflammatory Bowel Disease Questionnaire (IBDQ) [9] and the Short Form Health Survey-36 (SF-36) [10] were used, as well as an originally designed questionnaire (with the permission of the authors, for IBDQ, License Agreement ORCIP file number: IBDQ07-032, McMaster University, Hamilton, Ontario, Canada).

All questionnaires were sent to patients, together with a form of consent to participate in the research and information about the research objectives and how to fill in the forms.

The IBDQ is a specific questionnaire, assessing the quality of life in an objective dimension. It consists of 32 questions that are scored from 1 (there is a problem or a symptom) to 7 (no problem or symptom). Thus, a higher score (maximum: 224 points) indicates better QoL, and a lower score (minimum: 32 points) indicates worse QoL. The QoL is examined here in terms of biological and psychosocial aspects. The questions cover four areas:

1) intestinal symptoms - the number of evacuations, the presence of soft faeces, cramps and abdominal pain, flatulence, rectal bleeding, involuntary soiling of underwear, nausea and stomach discomfort (score of 1 - 70);

2) systemic symptoms - fatigue, frustration, impatience, anxiety, vigour, insomnia, weight loss (score of $1-35$ );

3) emotional aspects - the need for surgical treatment, fear of inability to find a toilet, feeling of discouragement and depression, fear and anxiety, feeling of relaxation and contentment, embarrassment associated with intestinal problems, unreasonable evacuation urgency, feeling of nervousness, wrath, anger, irritability, lack of understanding from other people, a sense of happiness and personal satisfaction (score of 1-84);

4) social aspects - absenteeism at school or at work, dismissing social meetings, inability to carry on physical activity and leisure activity according to preferences, avoiding places with no access to toilets, sexual activity (score of $1-35$ ) [9].

The non-specific questionnaire SF-36 measures the QoL in a subjective dimension. It is an 11-point scale consisting of 36 statements, evaluating the quality of life at the physical and psychological level, as well as indicating the independence of the patient in terms of simple and complex everyday activities.

The physical area includes the following sections:

a) Physical Functioning (PF) - evaluates the influence of health on physical activity;

b) Physical Role Functioning (RP) - shows the influence of health on professional and personal life;

c) Body Pain (BP) - evaluates the influence of pain on everyday life;

d) General Health $(\mathrm{GH})$ - subjective evaluation of heath. The psychological area is characterised by the following sections:

a) Vitality (VT) - evaluates life energy;

b) Social Role Functioning (SF) - evaluates the influence of the disease on social relations;

c) Emotional Role Functioning (RE) - describes the way in which the disease affects the quality of activities performed in the workplace and at home;

d) Mental Health $(\mathrm{MH})$ - evaluates feelings of happiness and depression.

In the Polish version of the scale a higher score (maximum: 171 points) indicates worse quality of life, while a lower score indicates better quality of life $[9,11]$.

The questionnaire consisted of 15 questions regarding demographic and clinical data of the study group: age, sex, place of residence, education, professional status, marital status, having children, sharing a house or living alone, religion, duration of the disease, its location, medical treatment, surgical treatment, coexisting diseases, and current health situation. 


\section{Statistical analysis}

In order to characterise the study groups and variables, the following measures of descriptive statistics were used: percentage, arithmetic mean, standard deviation and median.

To analyse the differences in various areas of life in IBDQ and SF-36 and to analyse the relationship between quality of life and selected factors (sex, place of residence, education, type of work, marital status, duration of the disease, and the type of operation performed), a randomised one-way analysis of variance (ANOVA) was used, preceded by Levene's test (in order to verify the homogeneity of variance). A post-hoc test verified which pairs of the areas differed, and which did not.

All calculations were carried out using Rundom Pro 3.14 software.

\section{Results}

Of the respondents, $17 \%$ were aged $26-30$ years, $17 \%$ were aged $41-45$ years, and people aged $51-55$,

Table I. Scores for IBDQ and SF-36

\begin{tabular}{llll} 
Scale & Mean & SD & Median \\
\hline $\begin{array}{l}\text { Inflammatory Bowel Disease } \\
\text { Questionnaire }\end{array}$ & & & \\
\hline General quality of life (32-224) & 152.51 & 6 & 161 \\
\hline $\begin{array}{l}\text { Short Form-36 } \\
\text { General quality of life (max. 171) }\end{array}$ & 115.94 & 40.97 & 58
\end{tabular}

Table II. Scores of different life areas according to IBDQ and SF-36

\begin{tabular}{lccc} 
Scale & Mean & SD & Median \\
\hline $\begin{array}{l}\text { Inflammatory Bowel Disease } \\
\text { Questionary': }\end{array}$ & & & \\
\hline Intestinal symptoms (1-70) & 47.14 & 31.58 & 47 \\
\hline Systemic aspects (1-35) & 20.03 & 13.4 & 20 \\
\hline Emotional aspects (1-84) & 61.2 & 27.5 & 64 \\
\hline Social aspects (1-35) & 24.43 & 11.25 & 25 \\
\hline Short Form-36 $:$ & & & \\
\hline PF - physical functioning & 25.67 & 11.79 & 9 \\
\hline RP - physical role functioning & 18.61 & 6.09 & 10 \\
\hline GH - general health perceptions & 19.11 & 6.44 & 10 \\
\hline V - vitality & 15.94 & 4.91 & 9 \\
\hline SP - social role functioning & 4.28 & 1.61 & 5 \\
\hline RE - emotional role functioning & 13.06 & 5.7 & 2 \\
\hline MH - mental health & 16.5 & 6.01 & 8 \\
\hline BP - bodily pain & 5.83 & 2.71 & 2 \\
\hline
\end{tabular}

${ }^{1} A$ higher score indicates better quality of life, ${ }^{2} A$ lower score indicates worse quality of life
$71-75$, and $76-80$ years constituted $3 \%$ in each range. People aged $20-25,31-35$, and $66-70$ years constituted $6 \%$ in each range. Nine percent of the respondents were aged $36-40$ and $46-50$ years, respectively. Ten percent of the respondents were aged $56-60$ years and $11 \%$ were aged $61-65$ years. Men made up the largest group - 68 (57\%) and those who live in the city 77 (14\%). Among respondents, $33.88 \%$ of patients had vocational education, $31.43 \%$ had secondary education, and $34.69 \%$ had completed higher education. There was a large group of patients who were retired (54.29\%). More than half of the respondents were married (57.14\%). 87.71\% declared cohabitation. The majority of respondents declared to be religious: 94 (29\%). 88.57\% of the respondents were after restorative proctocolectomy with formation of an internal pouch, and $11.43 \%$ were after complete removal of the large intestine with the emergence of ileostomy.

The most common symptoms declared by the respondents, accompanying the current health situation, were: abdominal and rectal pain, distension, soft faeces, frequent and uncontrollable evacuation, inflammation around the anus, inflammation of the reservoir, anaemia, weakness, irritability, constipation, psychological discomfort due to stoma, metabolic disorders, and involuntary soiling of underwear.

Medical treatment included the following drugs: sulfasalazine, loperamide, methylprednisolone, mesalazine.

The IBDQ scale assessed the objective aspect of life. The mean, standard deviation, and median were calculated on the basis of the result score (Table I).

The mean of the IBDQ scale was 152.51, and the median was 161 . In this scale, a higher score indicates better quality of life. The situation in the subjective SF-36 scale is reversed: a lower score indicates better quality of life. The mean of the SF-36 was 115.94, and the median was 58 (Table I).

The quality-of-life areas evaluated in the study with the IBDQ scale were as follows: intestinal symptoms, systemic symptoms, social and emotional aspects. The arithmetic means of each domain are relatively high (Table II). The test statistic was $\mathrm{F}=79.63, p=0.00001$, with a significance level of $p<0.05$.

The SF-36 performed statistical verification in the physical and mental areas. The low mean values described the area of social role functioning (4.28) and bodily pain (5.83), and the high mean values described the area of physical functioning (25.67), general health perception (19.11), and physical role functioning (18.61) (Table II). The value of the test statistics for the SF-36 was $F=10.54, p=0.00001$, with a significance level of $p<0.05$. A post-hoc test verified which areas differ significantly in both scales, as shown in Figures 1 and 2 . 


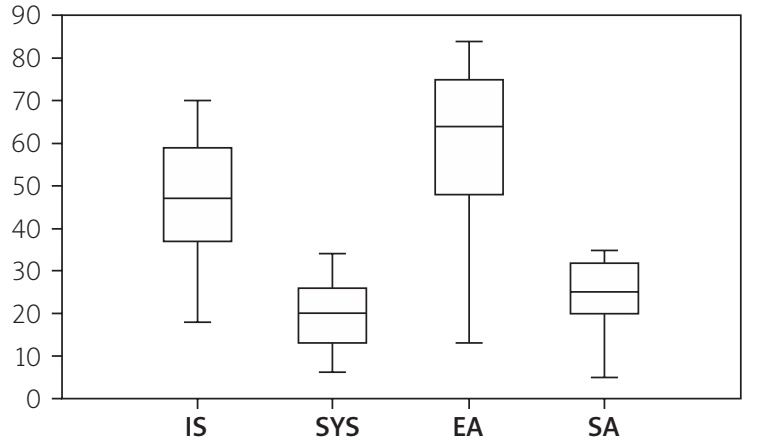

Figure 1. Quality of life in the areas of IBDQ scale IS - intestinal symptoms, SYS - systemic symptoms, EA - emotional aspects, $S A$ - social aspects

Table III. Scores of education in IBDQ and SF-36

\begin{tabular}{lccc} 
Scale & Mean & SD & Median \\
\hline $\begin{array}{l}\text { Inflammatory Bowel Disease } \\
\text { Questionarie: }\end{array}$ & & & \\
\hline University education & 172.45 & 42.7 & 170 \\
\hline $\begin{array}{l}\text { Secondary education } \\
\text { Vocational education }\end{array}$ & 158.33 & 41.23 & 170 \\
\hline $\begin{array}{l}\text { Short Form-362: } \\
\text { University education }\end{array}$ & 42.54 & 30.59 & 27 \\
\hline $\begin{array}{l}\text { Secondary education } \\
\text { Vocational education }\end{array}$ & 56.33 & 35.9 & 53 \\
\hline
\end{tabular}

'A higher score indicates better quality of life, ${ }^{2} \mathrm{~A}$ lower score indicates worse quality of life

Factors taken into account in the assessment of quality of life were as follows: gender, place of residence, education, employment status, marital status, duration of the disease, and surgical treatment. Statistical analysis showed that there is a relation only between quality of life and education. It was divided into the following levels: university, secondary, and vocational education. ANOVA test statistic value in the IBDQ scale is $F=3.504, p=0.044, p<0.05$. The mean for people with university education was 172.45 , and for those with vocational education it was 125.18 (Table III, Figure 3).

In SF-36 ANOVA $(p>0.05)$ was $F=4.414, p=0.022$. Post-hoc tests indicate significant differences between vocational and university education, $p=0.015$ (Table III, Figure 4).

\section{Discussion}

The results of the research show that somatic complaints significantly influence the quality of life (it is

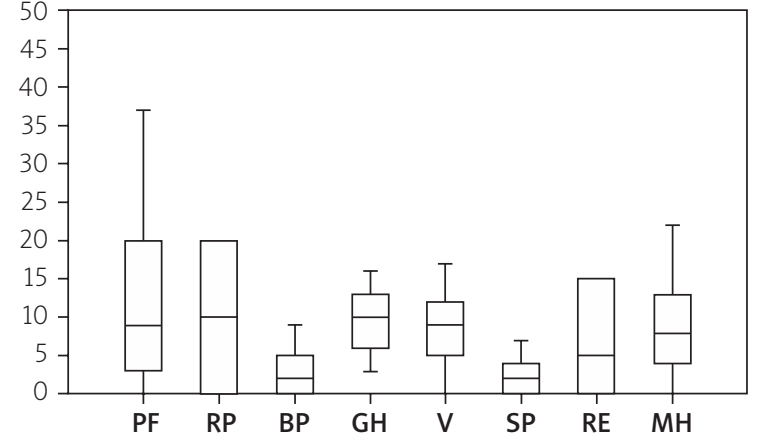

Figure 2. Quality of life in the areas of SF-36 scale

$P F$ - physical functioning, $R P$ - physical role functioning, $B P$ - bodily pain, $G H$ - general health perception, $V$-vitality, SP-social role functioning, $R E$ - emotional role functioning, $\mathrm{MH}$ - mental health

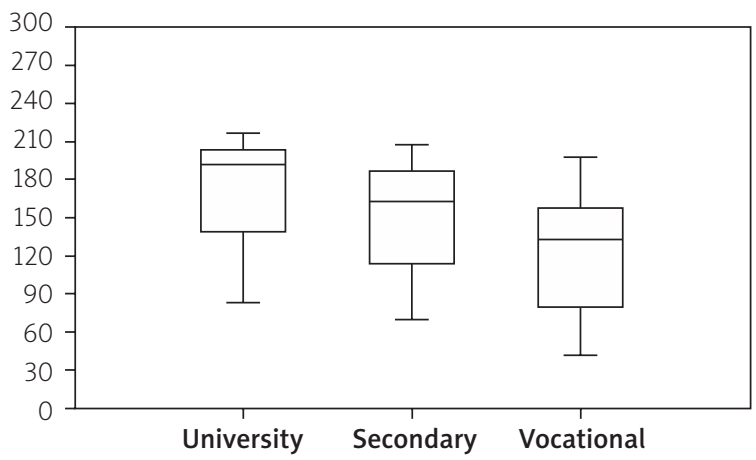

Figure 3. The relation between QoL and education, IBDQ scale

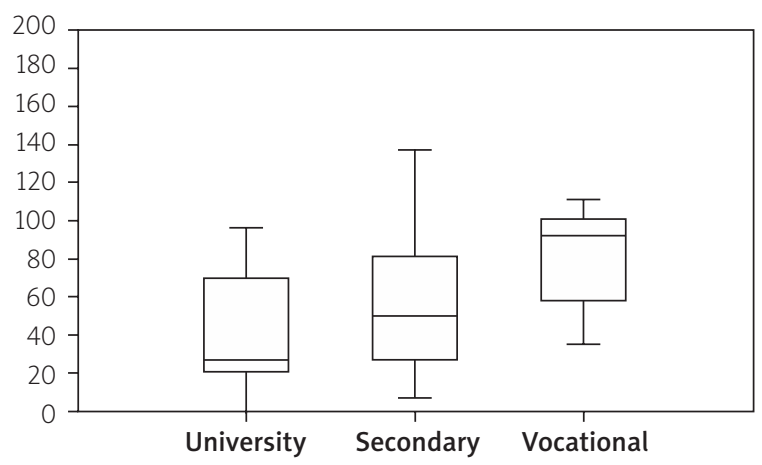

Figure 4. The relation between QoL and education, SF-36 scale

most visible in the SF-36 scale). Kurina et al. [12] and Kamrowska et al. [13] indicated the relation between physical disorders and mental health problems, such as stress, fear, and depression. This, in turn, leads to low emotional functioning of the patient and UC symptoms aggravation, as well as a higher frequency of relapses 
$[12,13]$. However, a primary psychological profile of the UC patients did not have an impact on their later psychological disorders [14].

According to Andrzejewska et al. [15], the dominant physical disorder among the patients was insomnia, i.e. a lack of or insufficient amount of sleep, nightmares, or trouble falling asleep. Next was pain that limited the patients' functional capacity. The "presence" of the disease also had a negative impact on the patients' mental health, impairing their ability to relax and rest, their social and physical activity, and their self-acceptance.

Additionally, Walewska et al. [16] and Skowron [17] researched the relation between quality of life and physical disorders. In these works it was stated that UC and related ailments force people with the disease to plan the whole day in advance, leaving no room for spontaneity. However, a longer time from diagnosis and longer disease duration indicated better quality of life. This might be a result of acceptance of the situation and of the disease itself.

Tuszewska et al. [18] also indicated that somatic problems might negatively affect patients' professional work. These problems may be caused by the employee, the employer, and/or co-workers. Nevertheless, Petryszyn et al. [19] state that such a situation does not arise among people working for many years with the same supervisor.

Guthrie et al. [20] and Casellas et al. [21] researched, among other things, the relation between the intensity of the disease and its duration, along with QoL. In their research, they proved the absence of such a relation. Their results are in contrast to the work of Neubauer et al. [22] and Bączyk et al. [11, 23], who referred to patients after surgical treatment and showed that the longer the duration and the more advanced the disease, the worse the psychological condition of the patient.

The relation between gender and quality of life was researched by Kamrowska et al. [13] and Walewska et al. [16]. The first work indicates low quality of life among women [12], whereas the other work shows the same thing for men [16]. On the other hand, Won Han et al. [24], Casellas et al. [21], and Bączyk et al. [11] proved no such relation. The same results were obtained concerning the influence of the patients' place of residence. Analysis of the patients' age and education gave different results, i.e. higher education and the age of 30 years positively influenced QoL.

More factors determining the quality of life were described by Andrzejewska et al. [25]. It has been proven that there is a relation between QoL and gender, place of residence, and education. Female gender, living in the countryside, and low education level significantly lower quality of life. Probably, women approach the disease more emotionally, because it affects not only their health, but also their physical appearance, sexuality, social life, and attractiveness. Living in the countryside may result in stigmatisation and reproduction of stereotypes (e.g. about an unpleasant smell and lack of personal hygiene).

The research also found a relationship between education and quality of life. Respondents with university education had higher quality of life than those with vocational education. This might be associated with having more knowledge and the ability to access information and to use it in practice.

Timmer et al. [26] referred in their work to the sexual issue of the diseased after an ileostomy. Here as well, women were more reluctant due to physical and psychological barriers. Chojnacki et al. [27] emphasise the importance of comprehensive treatment of patients for better quality-of-life assessment taking into account pharmacological treatment, dietary and surgical factors, support groups, and the need for psychological and psychiatric treatment. The main disturbances are emotional states of depression and anxiety. Therefore, therapy directed at a stable emotional state and cooperation with a psychologist and a psychiatrist helps patients to develop appropriate ways of coping with the disease.

Haller and Kemmler [28] called for support in the therapeutic process. It seems that family, friends, and medical personnel should be equally involved in patient support. Such a situation could positively affect the emotional and mental stability of the patients, and thus influence their quality of life. Janke et al. [29] postulate that psychiatrists should also work with the patients, as part of a standard therapy, because leaving patients alone to cope with the disease did not give favourable results [30].

There are not many studies on the quality of life in patients after a surgical intervention. However, most of them prove considerable improvement of the quality of life after surgery. This is connected with a reduction in physical symptoms, better nutrition, and better social contact (overcoming the feeling of shame and having a more active life) [31-33]. Similar results were obtained in our study with the use of the IBDQ scale. Nevertheless, as stated by Petryszyn et al. [19], there are patients who think that surgical intervention has a negative effect on the quality of life. This may result from the type of surgery performed and the presence of stoma, which is not accepted by everybody (e.g. for aesthetic reasons). The results presented by Petryszyn et al. [19] are compatible with the values obtained in the SF-36 scale in our study. 


\section{Conclusions}

The objective IBDQ scale showed better quality of life in UC patients treated surgically than did the subjective SF-36 scale. Quality of life varies in different domains of the IBDQ and SF-36 scales. The SF-36 scale showed poor quality of life in relation to the physical aspect, namely: physical functioning, general health perception, and physical role functioning. The relation between quality of life and education (university vs. vocational) has been proven. No relation has been found between quality of life and the following factors: gender, place of residence, marital status, professional status, disease duration, and type of surgery.

There is a need for further research in the area of quality of life, especially among UC patients after surgical intervention, because of a limited amount of works about the issue, and also because of different quality-of-life evaluation, depending on the therapy applied (pharmacological or surgical). Many discrepancies in the field (e.g. the influence of determining factors) create a niche for further studies. Moreover, quality-of-life evaluation may lead to better patient care, understanding their problems or treatment modifications, and finally may become a kind of therapy efficiency parameter.

\section{References}

1. Trojanowska A. The significance of research in quality of life in medicine [Polish]. Zdr Publ 2011; 121: 99-103

2. Eder P, Łodyga $M$, Eder P, Łodyga $M$, Łykowska-Szuber L, et al. Guidelines for the management of ulcerative colitis. Recommendations of the Working Group of the Polish National Consultant in Gastroenterology and the Polish Society of Gastroenterology [Polish]. Prz Gastroenterol 2013; 8: 1-20.

3. Lakatos PL. Recent trends in the epidemiology of inflammatory bowel diseases: up or down? World J Gastroentrol 2006; 12: 6102-8.

4. Daszykowska J. Life quality in concepts related to health [Polish]. Przegląd Medyczny Uniwersytetu Rzeszowskiego. Rzeszów 2006; 2: 122-8.

5. Papuć E. Quality of life-definitions and different types of approach [Polish]. Curr Probl Psychiatry 2011; 12: 141-5.

6. WHO Constitution 1946; WHO. Geneva. Switzerland.

7. Michalak A, Krawczyk K, Bocian R, et al. Quality of life [Polish]. Ginekol Prakt 2009; 2: 33-7.

8. Wnuk M, Marcinkowski JT. Quality of life as a pluralistic and multidisciplinary construct [Polish]. Probl Hig Epidemiol 2012; 93: 21-6.

9. Irvine EJ. Quality of life - measurement in inflammatory bowel disease. Scand J Gastroenterol 1993; 199: 22-7.

10. Tylka J, Piotrowicz R. Quality of life SF-36 questionnaire - the Polish version [Polish]. Kardiol Pol 2009; 67: 1166-9.

11. Bączyk G, Karoń J, Krokowicz P. The objective and subjective dimension of quality of life in patients with inflammatory bowel diseases treated on surgical wards [Polish]. Prz Gastroenterol 2011; 6: 170-5.
12. Kurina LM, Goldacre MJ, Yeates D, Gill LE. Depression and anxiety in people with inflammatory bowel disease. Epidemiol Community Health 2001; 55: 716-20.

13. Kamrowska A, Kasprzak K, Marciniak J, et al. Anxiety and depression in ulcerative colitis and Lesniovsky-Crohn's disease [Polish]. Pol Merk Lek 2010; 28: 239-41.

14. Graff LA, Walker JR, Lix L, et al. The relationship of inflammatory bowel disease type and activity to psychological functioning and quality of life. Clin Gastroenterol Hepatol 2006; 4: 1491-501.

15. Andrzejewska A, Talarska D. The quality of life in inflammatory bowel disease. The analysis and validation of a new research tool [Polish]. Prz Gastroenterol 2009; 4: 88-92.

16. Walewska E, Ścisło L, Kózka M, et al. Quality of life in patients suffering from colitis ulcerosa [Polish]. Annales Universitatis Mariae Curie-Skłodowska Lublin 2005; LX, Suppl. XVI, 597 SECTIO D: $147-51$

17. Skowron W. Quality of life in patients with ulcerative colitis [Polish]. Problemy Pielęgniarstwa 2011; 19: 361-4.

18. Tuszewska M, Tuszewski B. Quality of life and sense of coherence in patients with ulcerative colitis [Polish]. Nowiny Lekarskie 2002; 71: 207-11.

19. Petryszyn P, Semianow-Wejchert J, Annabhani A, Paradowski L. Quality of life, education, occupational and social status of patients with inflammatory bowel disease - literature review [Polish]. Gastroenterol Pol 2008; 15: 421-4.

20. Guthrie E, Jackson J, Shaffer J, et al. Psychological disorder and severity of inflammatory bowel disease predict health-related quality of life in ulcerative colitis and Crohn's disease. Am J Gastroenterol 2002; 97: 1994-9.

21. Casellas F, Arenas JI, Baudet JS, et al. Impairment of helath-related quality of life in patients with inflammatory bowel disease: a Spanish Multicenter Study. Inflamm Bowel Dis 2005; 11: 488-96.

22. Neubauer K, Arlukiewicz A, Paradowski L. Quality of life in inflammatory bowel disease. Adv Clin Exp Med 2009; 18: 79-83.

23. Bączyk G, Karoń J, Krokowicz P, et al. Assessing quality of life among patients with inflammatory bowel disease treatment on surgical ward. Proktologia 2008; 9: 172-82.

24. Won Han S, McColl E, Barten JR, et al. Predictors of quality of life in ulcerative colitis. The importance of symptoms and illness representations. Inflamm Bowel Dis 2005; 11: 24-34.

25. Andrzejewska A, Talarska D, Michalak M, Linke K. Quality of life in patients with Crohn's disease and ulcerative colitis. Comparative analysis [Polish]. Prz Gastroenterol 2009; 4: 251-5.

26. Timmer A, Bauer A, Dignass A, Rogler G. Sexual function in persons with inflammatory bowel disease: a survey with matched controls. Clin Gastroenterol Hepatol 2007; 5: 87-94.

27. Chojnacki C, Romanowski M, Wachowska-Kelly P. Psychosomatic complications during treatment for ulcerative colitis [Polish]. Prz Gastroenterol 2012; 7: 52-5.

28. Haller C, Kemmler G. Social network and social support in patients with chronic inflammatory bowel disease. Psychosom Med Psychother 2003; 49: 36-48.

29. Janke KH, Klump B, Gregor M, et al. Determinants of life satisfaction in inflammatory bowel disease. Inflamm Bowel Dis 2005; 11: 272-86. 
30. Larsson K, Lööf L, Rönnblom A, Nordin K. Quality of life for patients with exacerbation in inflammatory bowel disease and how they cope with disease activity. Psychosom Res 2008; 64: 139-48.

31. Szepes Z, Molnár T, Farkas K, et al. Better quality of life after surgery treatment in patients with colitis ulcerosa: what is the price. Orv Hetil 2010; 151: 1264-9.

32. Meyer AL, Teixeira MG, Almeida MG, et al. Quality of life in the late follow-up of ulcerative colitis patients submitted to restorative proctocolectomy with sphincter preservation over ten years ago. Clinics (Sao Paulo) 2009; 64: 877-83.

33. von Flüe M, Ott K. Surgical strategies in patients with inflammatory bowel disease. Ther Umsch 2003; 60: 165-73.

Received: 5.12 .2013

Accepted: 1.05.2014 